\title{
Two-dose HPV regimen recommended in US
}

\author{
Cite as: CMAJ 2017 January 9;189:E36. doi: 10.1503/cmaj.109-5350
}

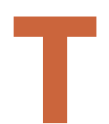

he Centers for Disease Control and Prevention (CDC) has changed its dosage recommendation for the human papillomavirus (HPV) vaccine for younger adolescents in the United States. It now recommends two doses of the vaccine for youths aged 11-12, taken at least six months apart, instead of three doses.

"Safe, effective, and long-lasting protection against HPV cancers with two visits instead of three means more Americans will be protected from cancer," Dr. Tom Frieden, director of the CDC, said in a media release. "This recommendation will make it simpler for parents to get their children protected in time."

The CDC still recommends three doses for older youth and young adults, between the ages of 15 and 26 . The new recommendation is based on a review of data that indicated two doses in younger adolescents produced a similar, and in some cases superior, immune response as three doses in older children and young adults. According to the CDC, about $60 \%$ of girls and $50 \%$ of boys in the US have started the HPV-vaccine series. The government is aiming for overall coverage of $80 \%$ by 2020 .

"In brief, this is great news from CDC, which should translate into higher coverage of HPV vaccination," Dr. Eduardo Franco, chairman of the department of oncology at McGill University, said in an email.

According to Franco, fewer doses can help boost coverage in several ways. A two-dose regimen is easier to complete and adhere to than a three-dose regimen. It will be easier for physicians to convince parents to bring their pre-teens in for two doses than the previous "convoluted" schedule that required additional visits at

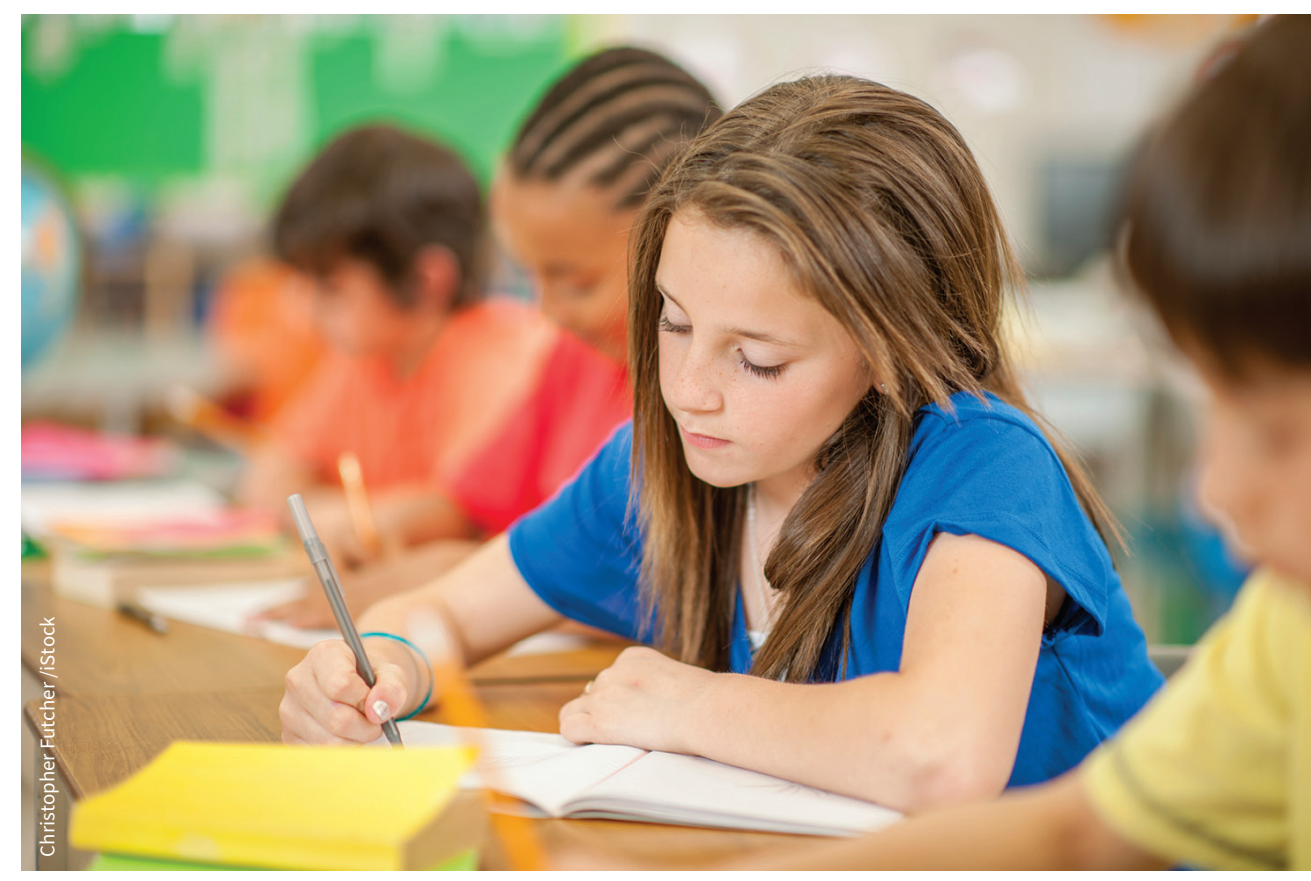

The CDC now recommends two doses of the HPV vaccine for youths aged 11-12 instead of three doses.

two and six months. Also, vaccinehesitant parents may believe the lower dosage is safer for their children.

"The potential benefits presumably include decreased cost, possible increased compliance and possible decreased risk of adverse events," Leah Smith, an epidemiologist with the Canadian Cancer Society, added in an email.

"Canada has been doing this for quite some time. Quebec was the first jurisdiction in the world to use two does at age 10," noted Franco. "Now, most provinces use a two-dose regimen ... Alberta is the noted exception, maintaining three doses at Grade 5."

The National Advisory Committee on Immunizations has recommended a twodose regimen in Canada for youth aged
9-14 since February 2015. "In the absence of vaccination, it is estimated that $75 \%$ of sexually active Canadians will have a sexually transmitted HPV infection at some point in their lives," stated the committee.

In its recently released Canadian Cancer Statistics 2016, the Canadian Cancer Society estimated that 4400 Canadians will be diagnosed with an HPV cancer in 2016 and 1200 will die from one. HPV can cause cancer of the cervix, mouth, throat, anus, vagina and penis. Vaccination rates across Canada range from $43 \%$ to $91 \%$, and only two provinces (Prince Edward Island and Newfoundland and Labrador) have rates over $80 \%$.

\section{Roger Collier, CMAJ}

